\title{
Automatic Target Acquisition and Bull Tracker using GPS and GSM Technology
}

\author{
P. Jayarajan, S. Shri Charan Ragul, V. Sri Yogesh, D. Ramvel
}

\begin{abstract}
An efficient bull tracking system is designed and implemented for tracking the movement of any bull from any location at any time. The designed device works using GPS and GSM technology for bull tracking. Arduino microcontroller is used to control the GPS and GSM module. The device is embedded on a bull whose position is to be determined and tracked in real time. The microcontroller is used to control the GPS module to get the coordinates at regular time intervals. The GSM module is used to transmit the updated coordinates of bull location to the client via SMS and mobile application. When the SMS is received, the app will automatically read the SMS and update the location of the bull to the user. This device will help the user to always keep an eye on their bull.
\end{abstract}

Index Terms- Arduino, GSM module, GPS module.

\section{INTRODUCTION}

A traditional event that takes place in Tamil Nadu is known as Jallikattu. At this event a bull is relinquished into a horde of people, and numerous human participants endeavor to grab the large hump on the bull's back with both arms and hang on to it while the bull endeavors to elude[7]. Bull Tracker offers an efficient, effective tracking system for managing animals. It provides exact location of the bull to the user. This is a Live tracking system which improves security with GPS and GSM system. The GPS module will get the latitude and longitude position of the bull and it will send to the database via GSM module .In [1], the location of the vehicle is monitored by installing a tracking system in it. We have innovated this idea to track bulls. It can track many number of bulls depending on the requirement of the user. It is used to track, monitor and analyse the current status of bull. The tracker is cost efficient, weightless and compact in size. We can access the data from anywhere and anytime with just a few clicks. It is mainly benefit for the users to see their bulls. Since it can show the position of the bulls in owner's mobile phone for this purpose an application is created[2] to track, monitor and analyse the current status of your bull and generates a report whenever user needed. Many farmers have

Revised Manuscript Received on February 15, 2020.

* Correspondence Author

P. Jayarajan*, Dept. of Electronics and Communication Engineering, Sri Krishna College of Technology, Coimbatore, India.

S. Shri Charan Ragul, Dept. of Electronics and Communication Engineering, Sri Krishna College of Technology, Coimbatore, India.

V. Sri Yogesh, Dept. of Electronics and Communication Engineering, Sri Krishna College of Technology, Coimbatore, India.

D. Ramvel, Dept. of Electronics and Communication Engineering, Sri Krishna College of Technology, Coimbatore, India.

(C) The Authors. Published by Blue Eyes Intelligence Engineering and Sciences Publication (BEIESP). This is an open access article under the CC BY-NC-ND license (http://creativecommons.org/licenses/by-nc-nd/4.0/) lost their bulls and they cannot track it due to the lack of tracking devices. We have innovated this "Automatic Target Acquisition and bull tracker" for efficient tracking of bulls.

\section{PROPOSED WORK}

- The main objective of this animal tracking system is for the jallikattu issue, the bulls which are used there are missing and are difficult to find. By using this tracking system they can be easily found.

- Time interval can be set according to the users' convenience i.e: every 2 seconds or every 10 minutes or every half an hour.

\section{SYSTEM DESIGN}

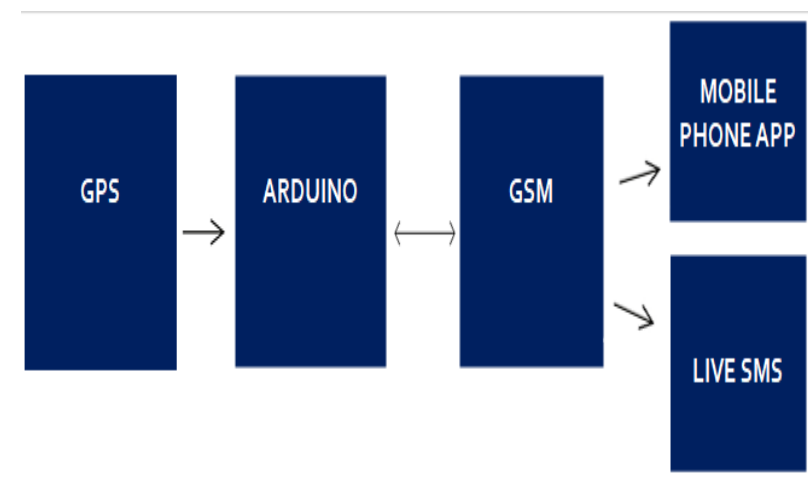

Fig.1 Block Diagram

The block diagram of this project is shown in Fig.1. In this project, Arduino is used for controlling the whole process with a GPS and GSM module. GPS is used for detecting coordinates of the bull, GSM module is used for sending the coordinates to the user through SMS and APP [5]. We have used GPS module NEO-6M and GSM module SIM800A.The GPS network consists of 27 satellites. Each satellite transmits a unique radio signal, which is processed by a specific GPS module. GPS extracts latitude and longitude coordinates from the satellite. GPS sends the extracted coordinates to the arduino. Arduino processes the locus information and sends it to GSM module. The GSM module receives the SMS from the system and sends it to the Arduino. Arduino scans the message and extract it from the entire one. After extracting it compares with its predetermined message. If the predefined and main message matches the arduino sends the coordinates of the location to the user through GSM [4]. This message contains the coordinates of bull location. 
We have developed an application which will show the current location of the bull by automatically reading the SMS [5]. When the hardware is programmed we can power it up and attach it with bulls.

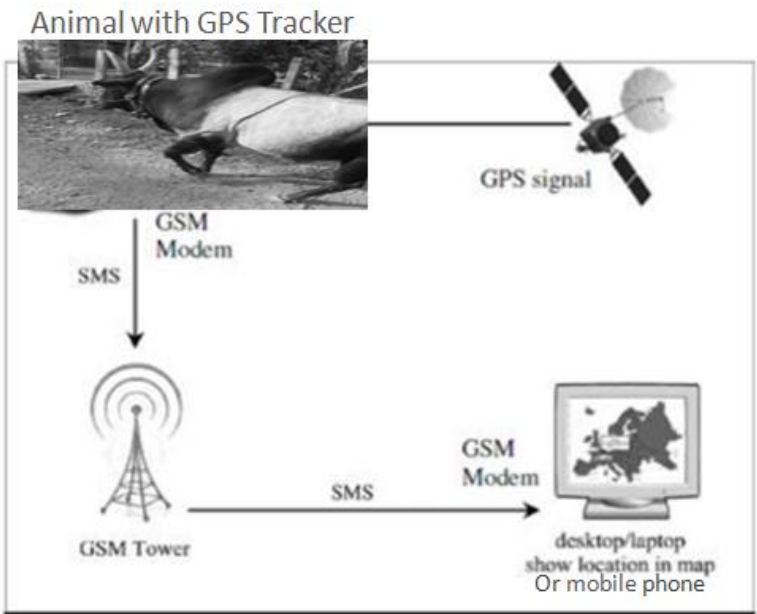

Fig.2 Logic diagram

This Bull tracking system takes input from GPS and send it through the GSM module[3] to desired mobile/laptop using mobile communication which is shown in Fig.2. Bull Tracking System is one of the biggest technological advancements to track the activities of the bull. The GPS module which is used by the security system to track the location or monitor the bull and then uses satellite or radio systems to send the coordinates and the location data to the user mobile [1]. Due to this technology bull tracking systems are becoming increasingly popular.

\section{HARDWARE IMPLEMENTATION}

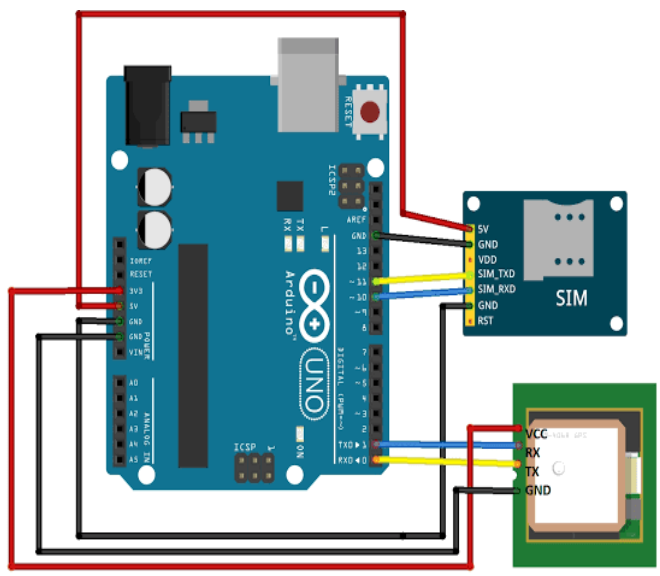

Fig.4 Circuit Diagram

Circuit Connections of bull tracking system are shown in Fig.4.In the above diagram the Tx pin of GPS module is directly connected to digital pin number $0(\mathrm{RX})$ of Arduino. By using Software Serial Library[6] here, Rx and Tx are connected serially through pin 0 and 1 respectively and the Rx pin of GPS Module is left open. VCC of GPS is connected to the $5 \mathrm{~V}$ pin of arduino. GND of GPS is paired with GND of arduino.The Tx and Rx pins of GSM and arduinos' 11 th and 10th pins are paired respectively. GSM module is also powered by $12 \mathrm{v}$ adaptor. The whole device is powered using power bank. Fig.5 represents the flow chart for the whole process of our tracking system.

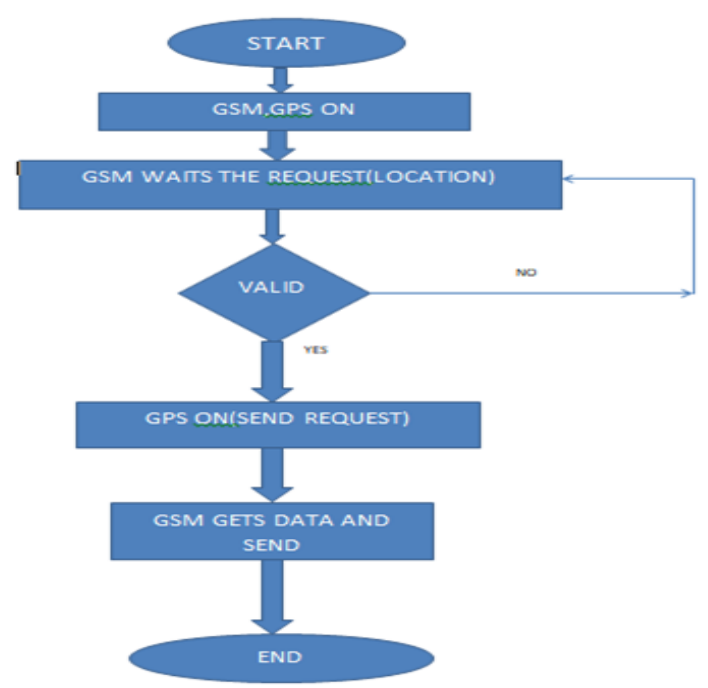

Fig.5 Flow Chart

\section{V.RESULT AND DISCUSSION}

We have developed a bull tracking system which is shown in Fig 6(a).The GSM modem was configured and we tested and implemented the tracking system Fig. 6(b) to monitor the bull location via SMS and application Fig.7\&8. To display the update in position of bull we have created an application which is shown in Fig.9(a,b). The Arduino is the brain of the system and the GSM modem is controlled by Arduino that enable data transmission over GSM network while the GPS provide the location data. Whenever the GPS receives a new data it is updated in the arduino and hence we are able to see the location on the app. Our device can provide good control on bull tracking. The system provides accurate data in real time that makes it possible for the user to track the bull. By using our idea various other applications can be developed.

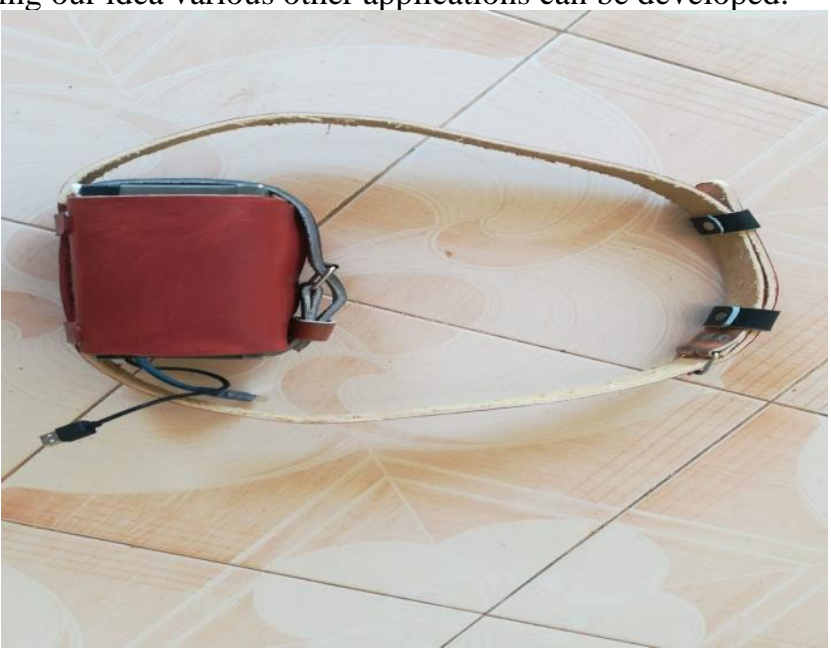

Fig.6 (a)

Published By:

Blue Eyes Intelligence Engineering 


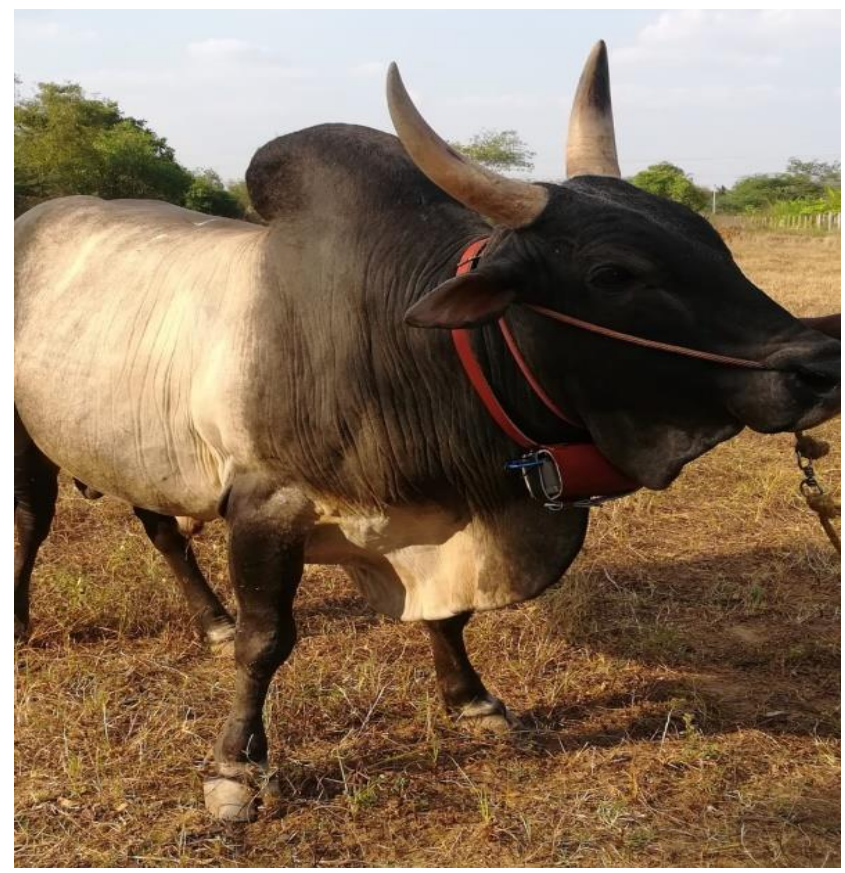

Fig.6 (b)

Fig.6 (a) \& Fig.6 (b) is Bull tracker kit and Real time implementation of tracker in bull.

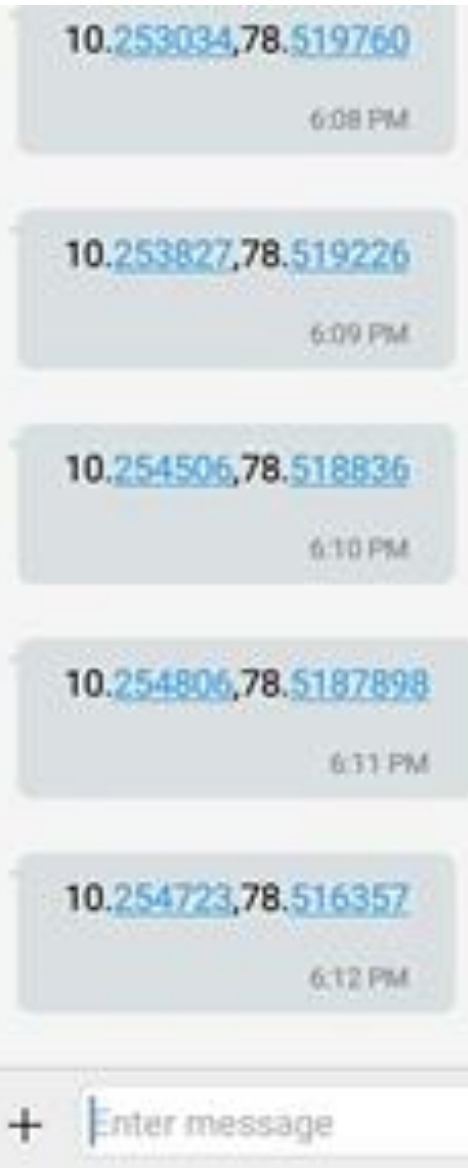

Fig.7

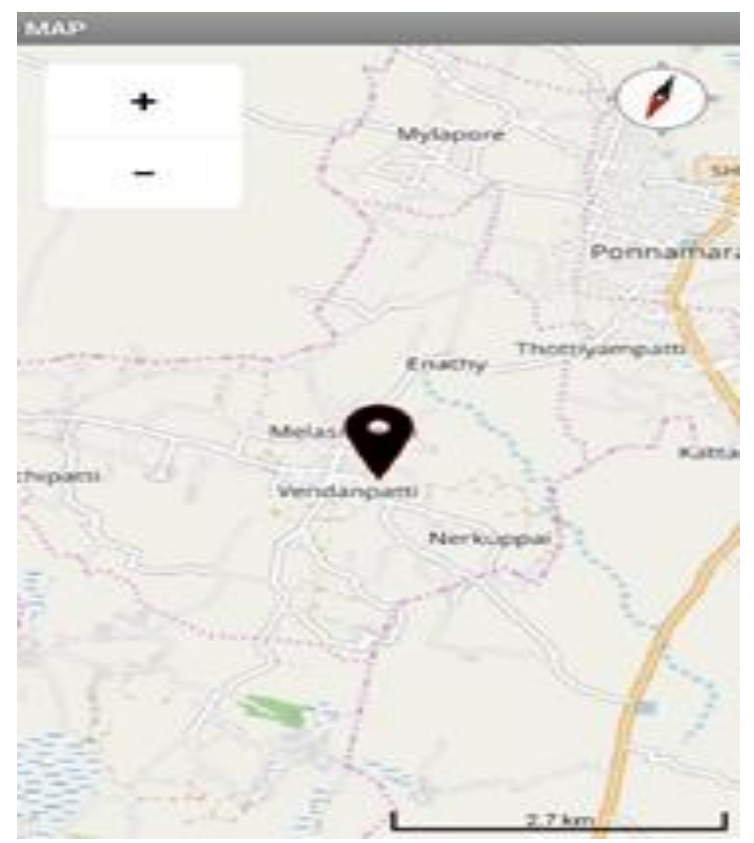

Fig.8

Fig.7 \& Fig.8 is SMS with Coordinates and View of Bull Location

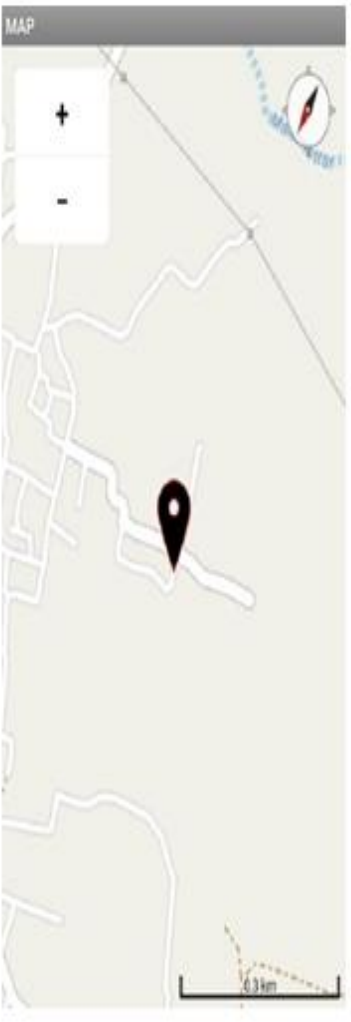

Fig.9(a)

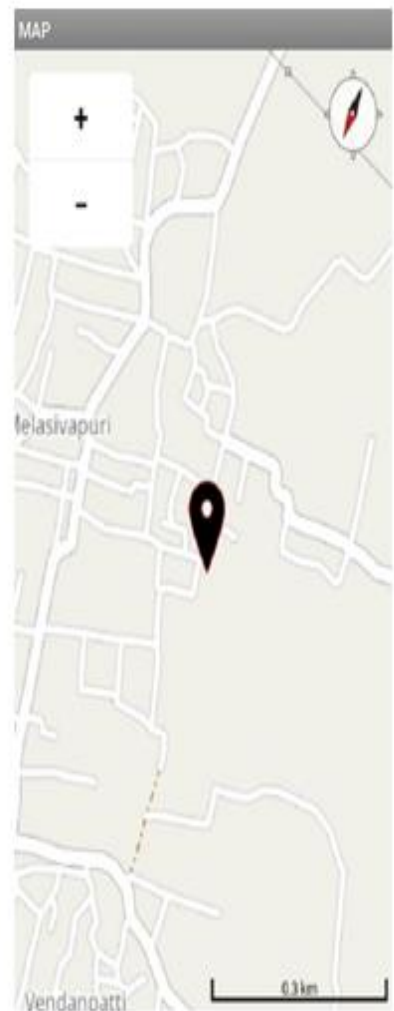

Fig.9(b)
Fig.9(a, b)-Variation in movement of bull location viewed through our application

Published By: 


\section{Automatic Target Acquisition and Bull Tracker using GPS and GSM Technology}

\section{CONCLUSION}

The device was tested and was found that the location of the animal was predicted effectively in most of the cases. We made the bulls which are participating in the jallikattu wear this tracker.By using this tracker the security of the bulls will be increased so that the lost bulls in jallikattu tied with this device can be quickly found. However, the location shown in the mobile can have an error of approximately 10 meters due to limitation in the hardware. In the future an upgraded version of our project will be developed which consists of increasing the memory of the device by replacing the controller with EEPROM which can store previous positions upto 256 locations. The kit will be more compact when we place GPS+GSM in the same module and also the accuracy of the GPS receivers can be increased by placing high cost GPS receivers..

\section{REFERENCES}

1. Kunal Maurya, Mandeep Singh, Neelu Jain, "Real Time Vehicle Tracking System using GSM and GPS Technology- An Anti-theft Tracking System," International Journal of Electronics and Computer Science Engineering. ISSN 2277-1956/V1N3-1103-1107.

2. Wilson, C., Sandifer, A., \& Olmsted, A. (2017).“ Designing an assembly language using MIT App inventor”. 2017 12th International Conference for Internet Technology and Secured Transactions (ICITST).

3. Gu, G., \& Peng, G. (2010). "The survey of GSM wireless communication system”. 2010 International Conference on Computer and Information Application.

4. Kim, S.-H., Kim, D.-H., \& Park, H.-D. (2016). “Animal Situation Tracking Service Using RFID, GPS, and Sensors".

5. N. Jahan, K. Hossen and M. K. H. Patwary, "Implementation of a vehicle tracking system using smartphone and SMS service," 2017 4th International Conference on Advances in Electrical Engineering (ICAEE), Dhaka, 2017, pp. 607-612.

6. https://en.m.wikipedia.org/wiki/Arduino

7. https://en.wikipedia.org/wiki/Jallikattu

\section{AUTHORS PROFILE}

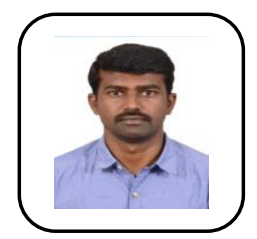

P. Jayarajan, has completed his B.E (EEE) from Madurai Kamaraj University in the year 2004, M.E(Applied Electronics) from Anna University in the year 2008 and Ph.D in the field of Wireless Sensor Network from Anna University in the year 2018.He has about 11 years of teaching experience and presently working as an Associate Professor in Electronics and Communication Engineering Department, Sri Krishna College of Technology, Coimbatore. He has published 15 papers at International journals and Conferences. His research interest includes Wireless Sensor Network, Modeling and Simulation.

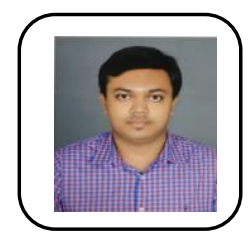

S. Shri Charan Ragul , UG student pursuing final year BE ECE (Electronics and Communication Engineering) at Sri Krishna College of Technology ,Coimbatore .His research interest includes Robotics, Embedded Systems, Wireless Communication Systems.

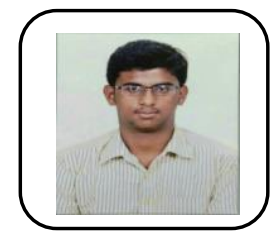

V. Sri Yogesh, UG student pursuing final year BE ECE (Electronics and Communication Engineering) at Sri Krishna College of Technology ,Coimbatore .His research interest includes Robotics, Embedded Systems, RTOS.

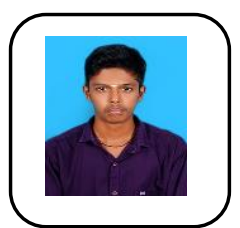

D. Ramvel, , UG student pursuing final year BE ECE (Electronics and Communication Engineering) at Sri Krishna College of Technology ,Coimbatore .His research interest includes Robotics, Embedded Systems, ARM processing. 